\title{
The past and the future of
} Alzheimer's disease CSF biomarkers-a journey toward validated biochemical tests covering the whole spectrum of molecular events

\section{OPEN ACCESS}

Edited by:

Sylvain Lehmann,

Montpellier University Hospital, France

Reviewed by:

Claudia Cicognola,

University of Perugia, Italy

Julien Dumurgier,

Université Paris Diderot - Paris 7 ,

France

*Correspondence:

Kaj Blennow,

Clinical Neurochemistry Laboratory,

Department of Psychiatry and

Neurochemistry, Institute of

Neuroscience and Physiology,

Sahlgrenska University Hospital, The

Sahlgrenska Academy at University of Gothenburg, Mölndal Campus,

SE-431 80 Mölndal, Sweden

kaj.blennow@neuro.gu.se

Specialty section:

This article was submitted to

Neurodegeneration,

a section of the journal

Frontiers in Neuroscience

Received: 29 May 2015 Accepted: 14 September 2015

Published: 29 September 2015

Citation:

Blennow K and Zetterberg H (2015)

The past and the future of Alzheimer's

disease CSF biomarkers - a journey

toward validated biochemical tests

covering the whole spectrum of

molecular events.

Front. Neurosci. 9:345.

doi: 10.3389/fnins.2015.00345

\section{Kaj Blennow* and Henrik Zetterberg}

Clinical Neurochemistry Laboratory, Department of Psychiatry and Neurochemistry, Institute of Neuroscience and Physiology, The Sahlgrenska Academy at University of Gothenburg, Mölndal, Sweden

This paper gives a short review on cerebrospinal fluid (CSF) biomarkers for Alzheimer's disease (AD), from early developments to high-precision validated assays on fully automated lab analyzers. We also discuss developments on novel biomarkers, such as synaptic proteins and $A \beta$ oligomers. Our vision for the future is that assaying a set of biomarkers in a single CSF tube can monitor the whole spectrum of AD molecular pathogenic events. CSF biomarkers will have a central position not only for clinical diagnosis, but also for the understanding of the sequence of molecular events in the pathogenic process underlying $A D$ and as tools to monitor the effects of novel drug candidates targeting these different mechanisms.

Keywords: Alzheimer disease, biomarker, cerebrospinal fluid, neurogranin, oligomers, synaptic proteins, tau proteins

Laboratory medicine tests influence up to $70 \%$ of clinical decisions and thus have a central position in clinical medicine (Beastall and Watson, 2013). Biochemical markers for chronic neurodegenerative disorders are especially important, since the slow progression and diffuse symptomatology results in diagnostic difficulties, and tissue sampling with direct visualization of central nervous system (CNS) pathology is not clinically applicable. For this reason, the Alzheimer's disease $(\mathrm{AD})$ arena is in the good situation that a set of highly validated and specific biomarkers are at hand; in addition to amyloid positron emission tomography (PET) and magnetic resonance imaging (MRI) measurements, a set of cerebrospinal fluid (CSF) tests reflecting key aspects of disease pathology are available. This paper comments on some caveats on the road to develop and validate these CSF biomarkers and some recent developments on novel biochemical tests.

\section{Early Assay Developments}

The story on modern AD biomarker development started in 1995 with a series of publications on enzyme-linked immunosorbent assays (ELISA) based on monoclonal antibodies to measure CSF levels of total tau (T-tau) and phosphorylated tau (P-tau) and the 42 amino acid isoform (Aß42) 
of $\beta$-amyloid (Blennow et al., 1995; Motter et al., 1995). These papers reported a marked increase in CSF T-tau and P-tau accompanied by a marked decrease in $\mathrm{A} \beta 42$ in $\mathrm{AD}$ (Blennow et al., 1995; Motter et al., 1995). The following years, many research reports consistently showed that the "AD profile" of increased CSF levels of T-tau and P-tau together with decreased $A \beta 42$ had high sensitivity and specificity, both in the range of $85-90 \%$, to identify AD dementia, for review see (Blennow and Hampel, 2003). Since these three CSF biomarkers reflect key elements of $\mathrm{AD}$ pathophysiology, i.e., neuronal degeneration ( $\mathrm{T}$ tau), tau pathology (P-tau), and amyloid plaques (A $\beta 42)$, they are often termed the "core" AD biomarkers (Hampel et al., 2004).

\section{The Problem with Studies Based on Clinical Diagnosis}

The vast majority of studies were cross-sectional and the diagnoses were based on the exclusion criteria published in 1984 by the National Institute of Neurological and Communicative Disorders and Stroke and the Alzheimer's Disease and Related Disorders Association (NINCDS-ADRDA). In the studies evaluating the diagnostic performance of CSF biomarkers, the diagnostic entity "probable AD" based on the NINCDS-ADRDA criteria, i.e., an exclusion diagnosis made on pure clinical grounds, was used as gold standard in the evaluation of the CSF biomarkers (McKhann et al., 1984). For logical reasons, the poor diagnostic accuracy of these criteria (Knopman et al., 2001), and the overlap in pathology between $\mathrm{AD}$ and other dementias, such as Lewy body dementia and vascular dementia (Blennow et al., 2006), made it impossible to achieve full diagnostic separation between $\mathrm{AD}$ and aging or other dementias using biomarkers.

\section{The Issue of Biomarker-positive Elderly}

The introduction of amyloid PET in the arsenal of $\mathrm{AD}$ biomarkers marked a major change in $\mathrm{AD}$ biomarker research, since it became clear that $20-30 \%$ of apparently healthy elderly showed positive on scans (Klunk, 2011). In 2006, the first study showed that high amyloid ligand retention on amyloid PET almost completely corresponds to low CSF A $\beta 42$ (Fagan et al., 2006), and vice versa, a finding that has been verified in numerous subsequent studies, for review see Blennow et al. (2015). This knowledge rather quickly changed the view on how to interpret low CSF A $\beta 42$ levels in cognitively intact elderly, from poor assay quality or biomarker performance to an indicator of preclinical AD.

In support of this, reliable biomarkers for cerebral $\beta$ amyloidosis also made it possible to follow cognitively normal $\mathrm{A} \beta$-positive individuals over time. Such longitudinal studies are relevant given the fact that many individuals with $\mathrm{AD}$ neuropathology could be dementia-free when they died. Longitudinal $A \beta$ biomarker studies suggest that the majority of $A \beta$-positive individuals followed over many years develop cognitive impairment and eventually dementia. In other words, if the dementia-free individuals with AD neuropathology would have lived 5-10 years longer they would most likely have developed AD (Buchhave et al., 2012).

\section{Turning Direction Toward Early Diagnosis}

The failures of Phase 2 and 3 trials testing anti-A $\beta$ diseasemodifying drug candidates on $\mathrm{AD}$ patients in the dementia stage initiated a discussion on the whether this type of treatment need to be initiated before the dementia phase of the disease, i.e., before the neurodegenerative process is too severe and widespread (Blennow, 2010). An attractive option was therefore to perform further trails on $\mathrm{AD}$ patients in the mild cognitive impairment (MCI) stage of the disease. However, this would also introduce diagnostic challenges since MCI is a heterogeneous syndrome that may have many different underlying causes. Around 50$60 \%$ of MCI cases have prodromal AD (Dubois et al., 2007), meaning that they have underlying $\mathrm{AD}$ pathology and will progress to $\mathrm{AD}$ with dementia. MCI symptoms may also be caused by other neurodegenerative disorders such as Lewy body dementia and vascular dementia or be due to age-related benign cognitive disturbances, stress and depression. Further, symptoms in MCI cases are by definition vague and diffuse, which makes it impossible to diagnose AD clinically in unselected MCI cohorts (Petersen et al., 1999). This created a need to test if the CSF biomarkers have value also for early diagnosis.

In 1999, a first paper showed that MCI patients progressing to AD with dementia, which is sometimes called "converting," during the clinical follow-up period had the typical AD CSF profile of high T-tau and P-tau together with low A $\beta 42$, and levels were equally abnormal in the MCI and the dementia stage in cases with longitudinal sampling (Andreasen et al., 1999). In the first studies, no MCI group with long clinical follow-up, which is needed to ascertain that stable MCI cases will not progress, was presented. The first study with an extended clinical followup period, showed that the AD CSF profile had a 95\% sensitivity for prodromal $\mathrm{AD}$ at a specificity of $83-92 \%$ against controls and stable MCI cases and MCI cases that proved to have other dementias (Hansson et al., 2006). A series of large multi-center studies could verify such a high diagnostic accuracy of the AD CSF biomarker profile to identify prodromal AD (Mattsson et al., 2009; Shaw et al., 2009; Visser et al., 2009).

\section{Entering Diagnostic Criteria}

In 2007, the International Work Group (IWG) published the first research criteria for the diagnosis of prodromal AD for New Research Criteria for the Diagnosis of AD (Dubois et al., 2007). These criteria provided a new conceptual framework stating that $\mathrm{AD}$ could be diagnosed based on the combination of a clinical phenotype of episodic memory disturbances and one or more abnormal $\mathrm{AD}$ biomarker including CSF biomarkers (A $\beta$ and tau proteins), volumetric MRI and amyloid PET) (Dubois et al., 2007). In 2011, similar, but not identical, criteria for MCI due to $\mathrm{AD}$ (Albert et al., 2011) and dementia due to AD (McKhann et al., 2011) were published by the National Institute on AgingAlzheimer's Association (NIA-AA) workgroups on diagnostic guidelines for $\mathrm{AD}$. The IWG criteria for prodromal $\mathrm{AD}$ and NIA-AA criteria for MCI due to $\mathrm{AD}$ are similar, and most cases fulfilling one set of criteria will also fulfill the other, but the NIA-AA criteria allow for assessment of the likelihood of 
being correctly diagnosed, with both amyloid and (neuronal) injury biomarker positive cases having the highest likelihood (Visser et al., 2012). In the updated IWG-2 criteria (Dubois et al., 2014), CSF biomarkers got a more central role, together with amyloid PET, due to their high diagnostic performance (Hansson et al., 2006; Li et al., 2007; Brys et al., 2009; Snider et al., 2009; van Rossum et al., 2012), while downstream topographical AD biomarkers, such as volumetric MRI and FDG- PET, were judged to function better in monitoring disease course in $\mathrm{AD}$.

\section{Cut-offs and Clinical Interpretation}

The issue of identifying unified cut-offs for the CSF biomarkers was brought up in the updated IWG-2 criteria (Dubois et al., 2014). For CSF biomarkers, this problem stems from differences in pre-analytical procedures between clinics and in analytical procedures between laboratories, and not the least from variability in manufacturing procedures for the assays, with batch-to-batch variations (Mattsson et al., 2013). To overcome these problems, several standardization initiatives have been launched with the aim to minimize this type of variability, including the Global Biomarker Standardization Consortium (GBSC) and the International Federation of Clinical Chemistry and Laboratory Medicine (IFCC) Work Group for CSF proteins, that aims to develop certified reference materials and methods to serve as "gold standards" for CSF biomarker measurements (Carrillo et al., 2013). These initiatives will, together with novel validated assays produced under rigorous quality control measures and CSF biomarker methods run on fully automated lab analyzers, allow to uniform cut-off levels for diagnosis, and a more widespread use of CSF biomarkers in the routine clinical diagnostic setting.

However, for common age-related disorders such as diabetes type II and hypertension, there is no distinct line between health and disease, and recommended cut-offs must therefore be based on estimations of risk and values in the individual patient must always undergo clinical interpretation. The situation is the same for $\mathrm{AD}$, with an increasing overlap in neuropathological changes (Mountjoy et al., 1983; Mann et al., 1984; Hansen et al., 1988) and in CSF biomarker levels (Andreasen et al., 1999a; Mattsson et al., 2012) between aging and AD with increasing age. Indeed, studies comparing the diagnostic performance of CSF biomarker levels (A $\beta 42)$ and amyloid PET show that the overlap around the proposed cut-off for both biomarker modalities (Mattsson et al., 2014) makes it questionable to dichotomize results into biomarker (CSF A $\beta 42$ or amyloid PET) "positive" or "negative." The tradition in Laboratory medicine is to report the actual concentration of a biomarker back to the clinician who based on clinical experience interprets biomarker values near the cut-off with caution.

Ratios such as T-tau/A $\beta 42$, combining one injury and one amyloid biomarker, are commonly evaluated in clinical biomarker studies, and often found to perform better than either biomarker alone. Even if this type of ratios show excellent diagnostic separation in selected $\mathrm{AD}$ and control populations, they may be difficult to implement in unselected populations in the clinic. This is since an increase in CSF T-tau in patients with minor stroke, encephalitis or CJD will have a very high ratio despite having normal $\mathrm{CSF} A \beta 42$, and thus no indication of amyloid pathology (Blennow et al., 2006).

\section{The Putative APOE Dependence of CSF A $\beta 42$}

The apolipoprotein $\mathrm{E}(A P O E) \varepsilon 4$ allele is the main genetic risk factor for AD (Bertram and Tanzi, 2008). In the late 1990ies, several studies reported that $\mathrm{AD}$ patients possessing the $A P O E \varepsilon 4$ allele had lower CSF A $\beta 42$ than those without this gene variant (Galasko et al., 1998; Hulstaert et al., 1999). This association is present also in cognitively normal elderly (Prince et al., 2004). In contrast, CSF tau levels do not depend on the $\varepsilon 4$ allele (Andreasen et al., 1999b).

These results raised the question whether the ApoE4 isoform modulates brain and CSF A $\beta$ levels through a physiological mechanism. Some studies on mice found that the ApoE isoforms differentially regulates $A \beta$ clearance, and suggested that the $A P O E$ genotype contribute to $\mathrm{AD}$ risk by differentially regulating clearance of $\mathrm{A} \beta$ the brain throughout life (Castellano et al., 2011; Verghese et al., 2013). In a clinical study challenging this hypothesis, MCI patients stratified by for cortical amyloid deposition as evaluated by amyloid PET, amyloid positive cases had low CSF A $\beta 42$ levels, and amyloid negative cases normal A 342 levels, independently of $\varepsilon 4$ status (Lautner et al., 2014). These findings indicate that the gene-dose dependent association between the APOE $\varepsilon 4$ allele and $\mathrm{A} \beta 42$ is caused by more severe amyloid deposition in patients that are $\varepsilon 4$ carriers. In support of this conclusion, there is no association between CSF A $\beta 42$ and the $A P O E \& 4$ allele in young individuals, that are likely to be free of brain amyloid deposition (Lautner et al., 2014), and thus no evidence of a physiological effect on $A \beta$ clearance in man. In addition, these findings show that there is no need for $A P O E$ allele-dependent cut-off levels for CSF A $\beta 42$.

\section{Compensating for Differences in Basic $A \beta$ Production - the A $\beta 42 / A \beta 42$ Ratio}

Except for $A \beta 42$, the CSF contains several other $A \beta$ isoforms, the most abundant variant being $A \beta 40$ (Portelius et al., 2006). Even if CSF $A \beta 40$ is relatively unchanged in $A D$, the CSF $A \beta 42 / A \beta 40$ has been suggested to have stronger diagnostic accuracy for AD compared to CSF A $\beta 42$ alone (Hansson et al., 2007). The explanation may be that the ratio normalizes individuals according to their $A \beta$ production level, so that low CSF A $\beta 42$ can be more easily detected in "high $\mathrm{A} \beta$ producers" and vice versa (Lewczuk et al., 2015). Recent studies show that the CSF $A \beta 42 / A \beta 40$ ratio is valuable also in the clinical setting (Dumurgier et al., 2015).

\section{The Everlasting Promise of Blood Biomarkers for AD}

The CSF is continuous with the brain extracellular space, with a free exchange of molecules that makes it possible to monitor 
brain biochemistry by CSF analyses. Nevertheless, since blood is more accessible than CSF, for which a lumbar puncture is needed, blood biomarkers are desirable both for clinical diagnosis or screening and for multiple sampling in clinical trials. However, there are several circumstances that make blood a more challenging matrix than CSF for brain biomarkers. First, peripheral blood (plasma and serum) and the brain are separated by the blood-brain barrier, making only a small fraction of brain proteins enter the bloodstream. Second, the minute amounts of brain proteins entering the blood will be diluted in a compartment containing very high levels of other proteins such as albumin and $\operatorname{IgG}$, introducing a high risk of interference in analytical methods (Blennow and Zetterberg, 2015). Third, brain proteins in the bloodstream will be subjected to degradation by proteases, degradation in the liver or clearance in the kidneys, which will introduce a risk of confounding data. As an example, the Australian Imaging Biomarkers and Lifestyle (AIBL) research team have reported that plasma $A \beta$ levels are influenced by inflammatory and renal function covariates and that absolute levels of either $A \beta 40$ or $A \beta 42$ do not associate with $A D$ or neocortical A $\beta$ burden (Rembach et al., 2014). These factors make development of blood biomarkers for chronic neurodegenerative disorders challenging and limits the potential of blood samples as biomarker sources for AD.

One possible approach is to apply hypothesis-free proteomics, lipidomics, and similar methods in the search for $\mathrm{AD}$ blood biomarkers. Such studies report combinations of proteins, lipids, metabolites, or other molecules that discriminate $\mathrm{AD}$ from controls, and propose such panels as novel AD blood biomarkers, for review see (Henriksen et al., 2014). These studies often screen a high number of unselected molecules, each showing a marked overlap between $\mathrm{AD}$ and controls. However, when combining a number of molecules using multivariate statistics, a diagnostic separation is found. This type of studies have several challenges. First, analytical standardization is difficult for a panel of analyses consisting of high number of proteins or molecules with different characteristics (O'Bryant et al., 2015). Second, pre-analytical factors, such as influence of age, gender, other diseases, medications, food-intake, or physical activity may vary considerably between these molecules, or are not known or not examined. Third, patient and control cohort differences may influence outcome, but the panel is often evaluated in a "training" and "validation" set of patients and controls from the same cohort. Last, but not least, the issue of potential statistical overfitting of data to identify a "biomarker panel" from a very large number of molecules in samples from a specific cohort with limited number of cases may introduce bias. For these reasons, such panels of molecules unrelated to $\mathrm{AD}$ pathogenesis often fail to replicate in independent clinical cohorts (Zhao et al., 2015), or alternative protein biomarker panels are proposed in the different studies (Henriksen et al., 2014).

\section{Biochemical Tests Covering the Whole Spectrum of Molecular Events}

Despite that the core CSF AD biomarkers reflect central pathogenic mechanisms of the disease, novel biomarkers to monitor additional important molecular mechanisms in $\mathrm{AD}$ are constantly sought. Two important aspects of $\mathrm{AD}$ pathophysiology are soluble oligomeric $A \beta$ species and synaptic dysfunction and degeneration.

\section{Oligomeric A $\beta$ May Give Clues to Disease Pathogenesis}

Amyloid plaques are composed of aggregated $A \beta$, but research during the last decade has put focus on soluble oligomers of $\mathrm{A} \beta$ that may inhibit long-term potentiation (LTP) and cause tau hyperphosphorylation and neuritic dystrophy (Walsh et al., 2002; Jin et al., 2011), possibly by specifically affecting synapses and disturbing synaptic signaling pathways (Pozueta et al., 2013). LTP is thought to be the key mechanism behind memory encoding, the possible causation between $\mathrm{A} \beta$ oligomers and synaptic dysfunction and damage has evolved into an active area of research. However, LTP cannot be measured in vivo in man, and a key question is whether there is a primary $A \beta$ oligomerinduced deficit in LTP in the early stages of AD, or whether the synaptic degeneration in $\mathrm{AD}$ causes memory impairment through other mechanisms, with LTP deficits being downstream consequences of the synaptic dysfunction and loss. Tools to study these molecular mechanisms in man would thus be valuable.

$\mathrm{A} \beta$ oligomers, ranging from dimers, trimers, dodecamers, and larger molecular weight species have been found to be present in CSF (Klyubin et al., 2008; Handoko et al., 2013). However, in addition to the molecular heterogeneity, CSF A $\beta$ oligomer levels are very low, making reliable quantification challenging. Indeed, different studies have applied a wide variety of methodologies to allow quantification of these soluble aggregates, such as fluorescence correlation spectroscopy (Pitschke et al., 1998), biobarcode assay (Georganopoulou et al., 2005), misfolded protein assay (Gao et al., 2010), ELISA with the same monoclonal antibody both for capture and detection (Fukumoto et al., 2010), flow cytometry based assays (Santos et al., 2012), immunoprecipitation and Western blot (Handoko et al., 2013), and ultrasensitive bead-based immunoassays (Savage et al., 2014). Several studies have found increased A $\beta$ oligomer levels in CSF of AD patients (Pitschke et al., 1998; Georganopoulou et al., 2005; Fukumoto et al., 2010; Gao et al., 2010; Handoko et al., 2013; Holtta et al., 2013; Savage et al., 2014), but with large overlap with control groups, while other studies have reported no change (Santos et al., 2012; Bruggink et al., 2013; Jongbloed et al., 2015) or lower levels (Sancesario et al., 2012).

The reason for these contradictory results is unclear, but may include analytical shortcomings, variability in how and in which type of oligomer assemblies are secreted from the brain to the CSF, instability of A $\beta$ oligomers in CSF or during the analytical procedures, or other factors. Nevertheless, if these analytical shortcomings and variability between studies can be overcome, CSF $A \beta$ oligomers measurements may provide important clues to disease pathogenesis when applied in longitudinal studies in the different stages of $\mathrm{AD}$ and related to both neuropsychological evaluations and other $\mathrm{AD}$ biomarkers such as amyloid PET and MRI measurements. However, the finding in several studies that CSF A $\beta$ oligomer levels correlate with disease severity, with higher CSF levels in more advanced disease (Fukumoto et al., 2010; Santos et al., 2012; Savage et al., 2014), 
does not support that they are associated with early disease pathogenesis.

\section{Synaptic Biomarkers Enter the Arena}

Synapses are the building blocks of neuronal networks. Synapses consist of a pre-synaptic unit with synaptic vesicles containing the neurotransmitters that upon release, regulated by a delicate machinery of pre-synaptic proteins, bind to post-synaptic receptors at the dendritic spines and activate a cascade of molecular events to advance the signal (Jahn and Fasshauer, 2012). Synaptic dysfunction and degeneration is likely the direct cause of the cognitive deterioration in AD. Synaptic degeneration is an early pathogenic event in $\mathrm{AD}$ (Masliah et al., 2001; Scheff et al., 2007), with synaptic loss being more tightly correlated with cognitive impairment than either plaque or tangle pathology (DeKosky and Scheff, 1990; Blennow et al., 1996; Sze et al., 1997). Thus, synaptic biomarkers may serve as a tool to study the link between the molecular pathology and cognitive symptoms.

As mentioned above, there is no method to measure LTP in man, but some synaptic proteins such as neurogranin has been shown to play a critical role in LTP (Wu et al., 2002; Huang et al., 2004). Neurogranin is highly concentrated in dendritic spines, and neurogranin levels are markedly reduced in the hippocampus and the frontal cortex in $\mathrm{AD}$, indicating loss of post-synaptic elements (Davidsson and Blennow, 1998; Reddy et al., 2005). A pilot study using immunoprecipitation and Western blot showed increased CSF levels of neurogranin in $\mathrm{AD}$ (Thorsell et al., 2010). The first study using a quantitative immunoassay showed a marked increase in CSF neurogranin in $\mathrm{AD}$ dementia and high levels predicted progression to $\mathrm{AD}$ dementia among MCI patients (Kvartsberg et al., 2014). Further, in amyloid positive MCI cases, high neurogranin correlated with a more rapid cognitive deterioration during clinical follow-up (Kvartsberg et al., 2014). Among proteins specific for the presynaptic part of the synapse, SNAP-25 CSF levels are clearly

\section{References}

Albert, M. S., DeKosky, S. T., Dickson, D., Dubois, B., Feldman, H. H., Fox, N. C., et al. (2011). The diagnosis of mild cognitive impairment due to Alzheimer's disease: recommendations from the National Institute on Aging-Alzheimer's Association workgroups on diagnostic guidelines for Alzheimer's disease. Alzheimer's Demen. 7, 270-279. doi: 10.1016/j.jalz.2011. 03.008

Andreasen, N., Hesse, C., Davidsson, P., Minthon, L., Wallin, A., Winblad, B., et al. (1999a). Cerebrospinal fluid beta-amyloid(1-42) in Alzheimer disease: differences between early- and late-onset Alzheimer disease and stability during the course of disease. Archiv. Neurol. 56, 673-680. doi: 10.1001/archneur.56.6.673

Andreasen, N., Minthon, L., Clarberg, A., Davidsson, P., Gottfries, J., Vanmechelen, E., et al. (1999b). Sensitivity, specificity, and stability of CSF-tau in $\mathrm{AD}$ in a community-based patient sample. Neurology 53, 1488-1494. doi: 10.1212/WNL.53.7.1488

Andreasen, N., Minthon, L., Vanmechelen, E., Vanderstichele, H., Davidsson, P., Winblad, B., et al. (1999). Cerebrospinal fluid tau and Abeta 42 as predictors of development of Alzheimer's disease in patients with mild cognitive impairment. Neurosci. Lett. 273, 5-8. doi: 10.1016/S0304-3940(99)00617-5 elevated in $\mathrm{AD}$, also in the prodromal phase of the disease (Brinkmalm et al., 2014a), probably reflecting the ongoing destruction of presynaptic terminals (Davidsson and Blennow, 1998; Brinkmalm et al., 2014b).

\section{Concluding Remarks}

Three CSF biomarkers reflecting the core pathological features of $\mathrm{AD}$ are available: T-tau (neurodegeneration), P-tau (tau hyperphosphorylation and, potentially, tangle formation), and $\mathrm{A} \beta 42$ (plaque pathology). According to revised clinical criteria, these markers may help diagnose AD more accurately and open up the possibility of detecting pre-dementia stages of the disease. At present, their most obvious utility is in clinical trials of novel disease-modifying treatments against $\mathrm{AD}$. In the future, they may help selecting the right treatment for individual patients by making it possible to assess which molecular pathology is most likely to cause the patient's symptom at different stages of the disease. Standardization efforts are now moving the CSF tau and $A \beta$ biomarker tests toward automated clinical-grade assays, which hopefully will become as established and standardized as clinical chemistry tests for other common human diseases. In addition, there is considerable promise that CSF biomarkers will provide in vivo measurement of a range of additional pathophysiological processes in AD. New biomarkers including synaptic proteins and $A \beta$ oligomers, will broaden the arsenal toward a panel that covers the whole spectrum of molecular events in AD. The application of such panels in longitudinal clinical studies will give essential additional information of the evolution of pathogenic processes in $\mathrm{AD}$.

\section{Acknowledgments}

The Torsten Söderberg Foundation at the Royal Swedish Academy of Sciences.

Beastall, G. H., and Watson, I. D. (2013). Clinical chemistry and laboratory medicine: an appreciation. Clin. Chem. Lab. Med. 51, 3-4. doi: 10.1515/cclm2012-0546

Bertram, L., and Tanzi, R. E. (2008). Thirty years of Alzheimer's disease genetics: the implications of systematic meta-analyses. Nat. Rev. Neurosci. 9, 768-778. doi: $10.1038 / \mathrm{nrn} 2494$

Blennow, K. (2010). Biomarkers in Alzheimer's disease drug development. Nat. Med. 16, 1218-1222. doi: 10.1038/nm.2221

Blennow, K., Bogdanovic, N., Alafuzoff, I., Ekman, R., and Davidsson, P. (1996). Synaptic pathology in Alzheimer's disease: relation to severity of dementia, but not to senile plaques, neurofibrillary tangles, or the ApoE4 allele. J. Neural Transm. 103, 603-618. doi: 10.1007/BF012 73157

Blennow, K., de Leon, M. J., and Zetterberg, H. (2006). Alzheimer's disease. Lancet 368, 387-403. doi: 10.1016/S0140-6736(06)69113-7

Blennow, K., and Hampel, H. (2003). CSF markers for incipient Alzheimer's disease. Lancet Neurol. 2, 605-613. doi: 10.1016/S1474-4422(03) 00530-1

Blennow, K., Mattsson, N., Scholl, M., Hansson, O., and Zetterberg, H. (2015). Amyloid biomarkers in Alzheimer's disease. Trends Pharmacol. Sci. 36, 297-309. doi: 10.1016/j.tips.2015.03.002 
Blennow, K., Wallin, A., Agren, H., Spenger, C., Siegfried, J., and Vanmechelen, E. (1995). Tau protein in cerebrospinal fluid: a biochemical marker for axonal degeneration in Alzheimer disease? Mol. Chem. Neuropathol. 26, 231-245.

Blennow, K., and Zetterberg, H. (2015). Understanding biomarkers of neurodegeneration: ultrasensitive detection techniques pave the way for mechanistic understanding. Nat. Med. 21, 217-219. doi: 10.1038/ nm. 3810

Brinkmalm, A., Brinkmalm, G., Honer, W. G., Frolich, L., Hausner, L., Minthon, L., et al. (2014a). SNAP-25 is a promising novel cerebrospinal fluid biomarker for synapse degeneration in Alzheimer's disease. Mol. Neurodegener. 9:53. doi: 10.1186/1750-1326-9-53

Brinkmalm, A., Brinkmalm, G., Honer, W. G., Moreno, J. A., Jakobsson, J., Mallucci, G. R., et al. (2014b). Targeting synaptic pathology with a novel affinity mass spectrometry approach. Mol. Cell. Proteom. 13, 2584-2592. doi: 10.1016/j.neurobiolaging.2011.09.006

Bruggink, K. A., Jongbloed, W., Biemans, E. A., Veerhuis, R., Claassen, J. A., Kuiperij, H. B., et al. (2013). Amyloid-beta oligomer detection by ELISA in cerebrospinal fluid and brain tissue. Anal. Biochem. 433, 112-120. doi: 10.1016/j.ab.2012.09.014

Brys, M., Pirraglia, E., Rich, K., Rolstad, S., Mosconi, L., Switalski, R., et al. (2009). Prediction and longitudinal study of CSF biomarkers in mild cognitive impairment. Neurobiol. Aging. 30, 682-690. doi: 10.1016/j.neurobiolaging.2007.08.010

Buchhave, P., Minthon, L., Zetterberg, H., Wallin, A. K., Blennow, K., and Hansson, O. (2012). Cerebrospinal fluid levels of beta-amyloid 142 , but not of tau, are fully changed already 5 to 10 years before the onset of Alzheimer dementia. Arch. Gen. Psychiatry. 69, 98-106. doi: 10.1001/archgenpsychiatry.2011.155

Carrillo, M. C., Blennow, K., Soares, H., Lewczuk, P., Mattsson, N., Oberoi, P., et al. (2013). Global standardization measurement of cerebral spinal fluid for Alzheimer's disease: an update from the Alzheimer's Association Global Biomarkers Consortium. Alzheimer's Demen. 9, 137-140. doi: 10.1016/j.jalz.2012.11.003

Castellano, J. M., Kim, J., Stewart, F. R., Jiang, H., DeMattos, R. B., Patterson, B. W., et al. (2011). Human apoE isoforms differentially regulate brain amyloid-beta peptide clearance. Sci. Transl. Med. 3, 89ra57. doi: 10.1126/scitranslmed.3002156

Davidsson, P., and Blennow, K. (1998). Neurochemical dissection of synaptic pathology in Alzheimer's disease. Int. Psychogeriatr 10, 11-23.

DeKosky, S. T., and Scheff, S. W. (1990). Synapse loss in frontal cortex biopsies in Alzheimer's disease: correlation with cognitive severity. Ann. Neurol. 27, 457-464. doi: 10.1002/ana.410270502

Dubois, B., Feldman, H. H., Jacova, C., Dekosky, S. T., Barberger-Gateau, P., Cummings, J., et al. (2007). Research criteria for the diagnosis of Alzheimer's disease: revising the NINCDS-ADRDA criteria. Lancet Neurol. 6, 734-746. doi: 10.1016/S1474-4422(07)70178-3

Dubois, B., Feldman, H. H., Jacova, C., Hampel, H., Molinuevo, J. L., Blennow, K., et al. (2014). Advancing research diagnostic criteria for Alzheimer's disease: the IWG-2 criteria. Lancet Neurol. 13, 614-629. doi: 10.1016/S14744422(14)70090-0

Dumurgier, J., Schraen, S., Gabelle, A., Vercruysse, O., Bombois, S., Laplanche, J. L., et al. (2015). Cerebrospinal fluid amyloid-beta $42 / 40$ ratio in clinical setting of memory centers: a multicentric study. Alzheimer's Res. Ther. 7, 30. doi: 10.1186/s13195-015-0114-5

Fagan, A. M., Mintun, M. A., Mach, R. H., Lee, S. Y., Dence, C. S., Shah, A. R., et al. (2006). Inverse relation between in vivo amyloid imaging load and cerebrospinal fluid Abeta42 in humans. Ann. Neurol. 59, 512-519. doi: 10.1002/ana.20730

Fukumoto, H., Tokuda, T., Kasai, T., Ishigami, N., Hidaka, H., Kondo, M., et al. (2010). High-molecular-weight beta-amyloid oligomers are elevated in cerebrospinal fluid of Alzheimer patients. FASEB J. 24, 2716-2726. doi: 10.1096/fj.09-150359

Galasko, D., Chang, L., Motter, R., Clark, C. M., Kaye, J., Knopman, D., et al. (1998). High cerebrospinal fluid tau and low amyloid beta42 levels in the clinical diagnosis of Alzheimer disease and relation to apolipoprotein E genotype. Arch. Neurol. 55, 937-945. doi: 10.1001/archneur.55. 7.937
Gao, C. M., Yam, A. Y., Wang, X., Magdangal, E., Salisbury, C., Peretz, D., et al. (2010). Abeta40 oligomers identified as a potential biomarker for the diagnosis of Alzheimer's disease. PLOS ONE 5:e15725. doi: 10.1371/journal.pone.00 15725

Georganopoulou, D. G., Chang, L., Nam, J. M., Thaxton, C. S., Mufson, E. J., Klein, W. L., et al. (2005). Nanoparticle-based detection in cerebral spinal fluid of a soluble pathogenic biomarker for Alzheimer's disease. Proc. Natl. Acad. Sci. U.S.A. 102, 2273-2276. doi: 10.1073/pnas.0409336102

Hampel, H., Mitchell, A., Blennow, K., Frank, R. A., Brettschneider, S., Weller, L., et al. (2004). Core biological marker candidates of Alzheimer's disease-perspectives for diagnosis, prediction of outcome and reflection of biological activity. J. Neural Transm. 111, 247-272. doi: 10.1007/s00702-0030065-Z

Handoko, M., Grant, M., Kuskowski, M., Zahs, K. R., Wallin, A., Blennow, K., et al. (2013). Correlation of specific amyloid-beta oligomers with tau in cerebrospinal fluid from cognitively normal older adults. JAMA Neurol. 70, 594-599. doi: 10.1001/jamaneurol.2013.48

Hansen, L. A., DeTeresa, R., Davies, P., and Terry, R. D. (1988). Neocortical morphometry, lesion counts, and choline acetyltransferase levels in the age spectrum of Alzheimer's disease. Neurology 38, 48-54. doi: 10.1212/WNL.38.1.48

Hansson, O., Zetterberg, H., Buchhave, P., Andreasson, U., Londos, E., Minthon, L., et al. (2007). Prediction of Alzheimer's disease using the CSF Abeta42/Abeta40 ratio in patients with mild cognitive impairment. Dement. Geriatr. Cogn. Disord. 23, 316-320. doi: 10.1159/000100926

Hansson, O., Zetterberg, H., Buchhave, P., Londos, E., Blennow, K., and Minthon, L. (2006). Association between CSF biomarkers and incipient Alzheimer's disease in patients with mild cognitive impairment: a follow-up study. Lancet Neurol. 5, 228-234. doi: 10.1016/S1474-4422(06)70355-6

Henriksen, K., O’Bryant, S. E., Hampel, H., Trojanowski, J. Q., Montine, T. J., Jeromin, A., et al. (2014). The future of blood-based biomarkers for Alzheimer's disease. Alzheimer's Demen. 10, 115-131. doi: 10.1016/j.jalz.2013. 01.013

Holtta, M., Hansson, O., Andreasson, U., Hertze, J., Minthon, L., Nagga, K., et al. (2013). Evaluating amyloid-beta oligomers in cerebrospinal fluid as a biomarker for Alzheimer's disease. PLOS ONE 8:e66381. doi: 10.1371/journal.pone.0066381

Huang, K. P., Huang, F. L., Jager, T., Li, J., Reymann, K. G., and Balschun, D. (2004). Neurogranin/RC3 enhances long-term potentiation and learning by promoting calcium-mediated signaling. J. Neurosci. 24, 10660-10669. doi: 10.1523/JNEUROSCI.2213-04.2004

Hulstaert, F., Blennow, K., Ivanoiu, A., Schoonderwaldt, H. C., Riemenschneider, M., De Deyn, P. P., et al. (1999). Improved discrimination of AD patients using beta-amyloid(1-42) and tau levels in CSF. Neurology 52, 1555-1562. doi: 10.1212/WNL.52.8.1555

Jahn, R., and Fasshauer, D. (2012). Molecular machines governing exocytosis of synaptic vesicles. Nature 490, 201-207. doi: 10.1038/nature11320

Jin, M., Shepardson, N., Yang, T., Chen, G., Walsh, D., and Selkoe, D. J. (2011). Soluble amyloid beta-protein dimers isolated from Alzheimer cortex directly induce Tau hyperphosphorylation and neuritic degeneration. Proc. Natl. Acad. Sci. U.S.A. 108, 5819-5824. doi: 10.1073/pnas.1017033108

Jongbloed, W., Bruggink, K. A., Kester, M. I., Visser, P. J., Scheltens, P., Blankenstein, M. A., et al. (2015). Amyloid-beta oligomers relate to cognitive decline in Alzheimer's disease. J. Alzheimer's Dis. 45, 35-43. doi: 10.3233/JAD142136

Klunk, W. E. (2011). Amyloid imaging as a biomarker for cerebral betaamyloidosis and risk prediction for Alzheimer dementia. Neurobiol. Aging. 32(Suppl. 1), S20-S36. doi: 10.1016/j.neurobiolaging.2011. 09.006

Klyubin, I., Betts, V., Welzel, A. T., Blennow, K., Zetterberg, H., Wallin, A., et al. (2008). Amyloid beta protein dimer-containing human CSF disrupts synaptic plasticity: prevention by systemic passive immunization. J. Neurosci. 28, 4231-4237. doi: 10.1523/JNEUROSCI.5161-07.2008

Knopman, D. S., DeKosky, S. T., Cummings, J. L., Chui, H., Corey-Bloom, J., Relkin, N., et al. (2001). Practice parameter: diagnosis of dementia (an evidence-based review). Report of the Quality Standards Subcommittee of the American Academy of Neurology. Neurology 56, 1143-1153. doi: 10.1212/WNL.56.9.1143 
Kvartsberg, H., Duits, F. H., Ingelsson, M., Andreasen, N., Öhrfelt, A., Andersson, K., et al. (2014). Cerebrospinal fluid levels of the synaptic protein neurogranin correlates with cognitive decline in prodromal Alzheimer's disease. Alzheimer's Dem. doi: 10.1016/j.jalz.2014.10.009. [Epub ahead of print].

Lautner, R., Palmqvist, S., Mattsson, N., Andreasson, U., Wallin, A., Palsson, E., et al. (2014). Apolipoprotein E genotype and the diagnostic accuracy of cerebrospinal fluid biomarkers for Alzheimer disease. JAMA Psychiatry 71, 1183-1191. doi: 10.1001/jamapsychiatry.2014.1060

Lewczuk, P., Lelental, N., Spitzer, P., Maler, J. M., and Kornhuber, J. (2015). Amyloid-beta $42 / 40$ cerebrospinal fluid concentration ratio in the diagnostics of Alzheimer's disease: validation of two novel assays. J. Alzheimer's Dis. 43, 183-191. doi: 10.3233/JAD-140771

Li, G., Sokal, I., Quinn, J. F., Leverenz, J. B., Brodey, M., Schellenberg, G. D., et al. (2007). CSF tau/Abeta42 ratio for increased risk of mild cognitive impairment: a follow-up study. Neurology 69, 631-639. doi: 10.1212/01.wnl.0000267428.62582.aa

Mann, D. M., Yates, P. O., and Marcyniuk, B. (1984). Alzheimer's presenile dementia, senile dementia of Alzheimer type and Down's syndrome in middle age form an age related continuum of pathological changes. Neuropathol. Appl. Neurobiol. 10, 185-207. doi: 10.1111/j.1365-2990.1984.tb 00351.x

Masliah, E., Mallory, M., Alford, M., DeTeresa, R., Hansen, L. A., McKeel, D. W. Jr., et al. (2001). Altered expression of synaptic proteins occurs early during progression of Alzheimer's disease. Neurology 56, 127-129. doi: 10.1212/WNL.56.1.127

Mattsson, N., Andreasson, U., Persson, S., Carrillo, M. C., Collins, S., Chalbot, S., et al. (2013). CSF biomarker variability in the Alzheimer's Association quality control program. Alzheimer's Demen. 9, 251-261. doi: 10.1016/j.jalz.2013.01.010

Mattsson, N., Insel, P. S., Landau, S., Jagust, W., Donohue, M., Shaw, L. M., et al. (2014). Diagnostic accuracy of CSF Ab42 and florbetapir PET for Alzheimer's disease. Ann. Clin. Trans. Neurol. 1, 534-543. doi: 10.1002/ acn3.81

Mattsson, N., Rosen, E., Hansson, O., Andreasen, N., Parnetti, L., Jonsson, M., et al. (2012). Age and diagnostic performance of Alzheimer disease CSF biomarkers. Neurology 78, 468-476. doi: 10.1212/WNL.0b013e3182477eed

Mattsson, N., Zetterberg, H., Hansson, O., Andreasen, N., Parnetti, L., Jonsson, M., et al. (2009). CSF biomarkers and incipient Alzheimer disease in patients with mild cognitive impairment. JAMA 302, 385-393. doi: 10.1001/jama. 2009.1064

McKhann, G., Drachman, D., Folstein, M., Katzman, R., Price, D., and Stadlan, E. M. (1984). Clinical diagnosis of Alzheimer's disease: report of the NINCDSADRDA Work Group under the auspices of Department of Health and Human Services Task Force on Alzheimer's Disease. Neurology 34, 939-944. doi: 10.1212/WNL.34.7.939

McKhann, G. M., Knopman, D. S., Chertkow, H., Hyman, B. T., Jack, C. R. Jr., Kawas, C. H., et al. (2011). The diagnosis of dementia due to Alzheimer's disease: recommendations from the National Institute on Aging-Alzheimer's Association workgroups on diagnostic guidelines for Alzheimer's disease. Alzheimer's Demen. 7, 263-269. doi: 10.1016/j.jalz.2011.03.005

Motter, R., Vigo-Pelfrey, C., Kholodenko, D., Barbour, R., Johnson-Wood, K., Galasko, D., et al. (1995). Reduction of beta-amyloid peptide42 in the cerebrospinal fluid of patients with Alzheimer's disease. Annal. Neurol. 38, 643-648. doi: 10.1002/ana.410380413

Mountjoy, C. Q., Roth, M., Evans, N. J., and Evans, H. M. (1983). Cortical neuronal counts in normal elderly controls and demented patients. Neurobiol. Aging 4, 1-11. doi: 10.1016/0197-4580(83)90048-9

O’Bryant, S. E., Gupta, V., Henriksen, K., Edwards, M., Jeromin, A., Lista, S., et al. (2015). Guidelines for the standardization of preanalytic variables for bloodbased biomarker studies in Alzheimer's disease research. Alzheimer's Dement. 11, 549-560. doi: 10.1016/j.jalz.2014.08.099

Petersen, R. C., Smith, G. E., Waring, S. C., Ivnik, R. J., Tangalos, E. G., and Kokmen, E. (1999). Mild cognitive impairment: clinical characterization and outcome. Arch. Neurol. 56, 303-308. doi: 10.1001/archneur.56.3.303

Pitschke, M., Prior, R., Haupt, M., and Riesner, D. (1998). Detection of single amyloid beta-protein aggregates in the cerebrospinal fluid of Alzheimer's patients by fluorescence correlation spectroscopy. Nat. Med. 4, 832-834. doi: $10.1038 /$ nm0798-832
Portelius, E., Westman-Brinkmalm, A., Zetterberg, H., and Blennow, K. (2006). Determination of beta-amyloid peptide signatures in cerebrospinal fluid using immunoprecipitation-mass spectrometry. J. Proteome Res. 5, 1010-1016. doi: $10.1021 /$ pr050475v

Pozueta, J., Lefort, R., and Shelanski, M. L. (2013). Synaptic changes in Alzheimer's disease and its models. Neuroscience 251, 51-65. doi: 10.1016/j.neuroscience.2012.05.050

Prince, J. A., Zetterberg, H., Andreasen, N., Marcusson, J., and Blennow, K. (2004). APOE epsilon4 allele is associated with reduced cerebrospinal fluid levels of Abeta42. Neurology 62, 2116-2118. doi: 10.1212/01.WNL.0000128088.08 695.05

Reddy, P. H., Mani, G., Park, B. S., Jacques, J., Murdoch, G., Whetsell, W. Jr., et al. (2005). Differential loss of synaptic proteins in Alzheimer's disease: implications for synaptic dysfunction. J. Alzheimer's Dis. 7, 103-117; discussion 73-80.

Rembach, A., Faux, N. G., Watt, A. D., Pertile, K. K., Rumble, R. L., Trounson, B. O., et al. (2014). Changes in plasma amyloid beta in a longitudinal study of aging and Alzheimer's disease. Alzheimer's Demen. 10, 53-61. doi: 10.1016/j.jalz.2012.12.006

Sancesario, G. M., Cencioni, M. T., Esposito, Z., Borsellino, G., Nuccetelli, M., Martorana, A., et al. (2012). The load of amyloid-beta oligomers is decreased in the cerebrospinal fluid of Alzheimer's disease patients. J. Alzheimer's Dis. 31, 865-878. doi: 10.3233/JAD-2012-120211

Santos, A. N., Ewers, M., Minthon, L., Simm, A., Silber, R. E., Blennow, K., et al. (2012). Amyloid-beta oligomers in cerebrospinal fluid are associated with cognitive decline in patients with Alzheimer's disease. J. Alzheimer's Dis. 29, 171-176. doi: 10.3233/JAD-2012-111361

Savage, M. J., Kalinina, J., Wolfe, A., Tugusheva, K., Korn, R., Cash-Mason, T., et al. (2014). A sensitive abeta oligomer assay discriminates Alzheimer's and aged control cerebrospinal fluid. J. Neurosci. 34, 2884-2897. doi: 10.1523/JNEUROSCI.1675-13.2014

Scheff, S. W., Price, D. A., Schmitt, F. A., DeKosky, S. T., and Mufson, E. J. (2007). Synaptic alterations in CA1 in mild Alzheimer disease and mild cognitive impairment. Neurology 68, 1501-1508. doi: 10.1212/01.wnl.0000260698.46517.8f

Shaw, L. M., Vanderstichele, H., Knapik-Czajka, M., Clark, C. M., Aisen, P. S., Petersen, R. C., et al. (2009). Cerebrospinal fluid biomarker signature in Alzheimer's disease neuroimaging initiative subjects. Ann. Neurol. 65, 403-413. doi: 10.1002/ana.21610

Snider, B. J., Fagan, A. M., Roe, C., Shah, A. R., Grant, E. A., Xiong, C., et al. (2009). Cerebrospinal fluid biomarkers and rate of cognitive decline in very mild dementia of the Alzheimer type. Arch. Neurol. 66, 638-645. doi: 10.1001/archneurol.2009.55

Sze, C. I., Troncoso, J. C., Kawas, C., Mouton, P., Price, D. L., and Martin, L. J. (1997). Loss of the presynaptic vesicle protein synaptophysin in hippocampus correlates with cognitive decline in Alzheimer disease. J. Neuropathol. Exp. Neurol. 56, 933-944. doi: 10.1097/00005072-199708000-00011

Thorsell, A., Bjerke, M., Gobom, J., Brunhage, E., Vanmechelen, E., Andreasen, N., et al. (2010). Neurogranin in cerebrospinal fluid as a marker of synaptic degeneration in Alzheimer's disease. Brain Res. 1362, 13-22. doi: 10.1016/j.brainres.2010.09.073

van Rossum, I. A., Vos, S. J., Burns, L., Knol, D. L., Scheltens, P., Soininen, H., et al. (2012). Injury markers predict time to dementia in subjects with MCI and amyloid pathology. Neurology 79, 1809-1816. doi: 10.1212/WNL.0b013e3182704056

Verghese, P. B., Castellano, J. M., Garai, K., Wang, Y., Jiang, H., Shah, A., et al. (2013). ApoE influences amyloid-beta (Abeta) clearance despite minimal apoE/Abeta association in physiological conditions. Proc. Natl. Acad. Sci. U.S.A. 110, E1807-E1816. doi: 10.1073/pnas.1220484110

Visser, P. J., Verhey, F., Knol, D. L., Scheltens, P., Wahlund, L. O., FreundLevi, Y., et al. (2009). Prevalence and prognostic value of CSF markers of Alzheimer's disease pathology in patients with subjective cognitive impairment or mild cognitive impairment in the DESCRIPA study: a prospective cohort study. Lancet Neurol. 8, 619-627. doi: 10.1016/S1474-4422(09) 70139-5

Visser, P. J., Vos, S., van Rossum, I., and Scheltens, P. (2012). Comparison of International Working Group criteria and National Institute on Aging-Alzheimer's Association criteria for Alzheimer's disease. Alzheimer's Demen. 8, 560-563. doi: 10.1016/j.jalz.2011.10.008 
Walsh, D. M., Klyubin, I., Fadeeva, J. V., Cullen, W. K., Anwyl, R., Wolfe, M. S., et al. (2002). Naturally secreted oligomers of amyloid beta protein potently inhibit hippocampal long-term potentiation in vivo. Nature 416, 535-539. doi: $10.1038 / 416535$ a

Wu, J., Li, J., Huang, K. P., and Huang, F. L. (2002). Attenuation of protein kinase $\mathrm{C}$ and cAMP-dependent protein kinase signal transduction in the neurogranin knockout mouse. J. Biol. Chem. 277, 19498-19505. doi: 10.1074/jbc.M109082200

Zhao, X., Lejnine, S., Spond, J., Zhang, C., Ramaraj, T. C., Holder, D. J., et al. (2015). A candidate plasma protein classifier to identify Alzheimer's disease. J. Alzheimer's Dis. 43, 549-563. doi: 10.3233/JAD-141149
Conflict of Interest Statement: The authors declare that the research was conducted in the absence of any commercial or financial relationships that could be construed as a potential conflict of interest.

Copyright $(2015$ Blennow and Zetterberg. This is an open-access article distributed under the terms of the Creative Commons Attribution License (CC BY). The use, distribution or reproduction in other forums is permitted, provided the original author(s) or licensor are credited and that the original publication in this journal is cited, in accordance with accepted academic practice. No use, distribution or reproduction is permitted which does not comply with these terms. 